\title{
Responsabilidad civil por daño ambiental. ¿Tutela efectiva de los derechos de los dañados o lirismo?*
}

\author{
Juan Espinoza Espinoza
}

\section{Introducción}

A partir de la revisión de la Ley General del Ambiente (en adelante, LGA) y su vinculación con la responsabilidad civil extracontractual, se analiza el caso de la minera Yanacocha, en relación con los derrames de mercurio ocurridos en junio del 2000. El artículo evidencia la falta de protección efectiva del medio ambiente, el insuficiente resarcimiento ofrecido a los directamente dañados y los vacíos normativos en la legislación nacional.

\section{Definición y alcances}

Antes de referirnos a la responsabilidad civil por daño ambiental, es imperativo delimitar los alcances del bien jurídico tutelado: el ambiente o medio ambiente. Así, el ambiente o hábitat natural es:

* Este artículo es resultado de la investigación realizada durante el año académico 2008 con el auspicio del Instituto de Investigación Científica de la Universidad de Lima. 
[...] aquello que la naturaleza (cosa-madre) ha producido y produce, con concurso o no, de la mano del hombre [...]. De tal manera, cualquier obra o intervención humana se traduce en obras o intervenciones "naturales", pues se insertan en el recorrido ya trazado por un ambiente encontrado y no alterado, pero progresivamente enriquecido por valores históricos y culturales, en el cual el hombre garantiza su sobrevivencia y desarrollo de su propia personalidad (Bigliazzi 1998: 1150).

No en balde el artículo IV del título preliminar de la LGA, Ley 28611, del 13 de octubre del 2005, establece:

Toda persona tiene el derecho a una acción rápida, sencilla y efectiva, ante las entidades administrativas y jurisdiccionales, en defensa del ambiente y sus componentes, velando por la debida protección de la salud de las personas en forma individual y colectiva, la conservación de la diversidad biológica, el aprovechamiento sostenible de los recursos naturales, así como la conservación del patrimonio cultural vinculado a aquellos.

Así, "el ambiente es un valor en conjunto, tiene un sustrato material; pero, considerado en sí mismo, es un valor" (Alpa 2001: 345). Ya en otra sede, partiendo de la definición de orden público (entendido como el conjunto de principio jurídicos, económicos, morales, políticos y de diversa índole, que son pilares de la estructura y el funcionamiento de la sociedad), se había hecho la distinción entre orden público estático (una suerte de muro de contención frente a la autonomía privada) y orden público dinámico (las condiciones que necesitan los ciudadanos para desarrollarse plenamente) (Espinoza 2005: 263). Por esta causa, el Estado se encuentra en la obligación de remover los obstáculos del caso. El artículo I del título preliminar de la LGA señala:

Toda persona tiene el derecho irrenunciable a vivir en un ambiente saludable, equilibrado y adecuado para el pleno desarrollo de la vida, y el deber de contribuir a una efectiva gestión ambiental y de proteger el ambiente, así como sus componentes, asegurando particularmente la salud de las personas en forma individual y colectiva, la conservación 
de la diversidad biológica, el aprovechamiento sostenible de los recursos naturales y el desarrollo sostenible del país.

Debido a ello, el bien jurídico atacado es "el medio ambiente en sus factores ecológicos y culturales. El interés jurídico es la calidad de vida in genere: es decir, considerada colectivamente, sin que deje ello de ser uninterés difuso" (Bustamante1997: 663). Resulta necesario pronunciarse acerca de los intereses difusos cuando se habla del daño ambiental. Se denominan así porque, a pesar de que pertenecen al individuo y pueden relevar en vía autónoma (como intereses particulares de la persona), se ubican en una dimensión supraindividual que no contradice su naturaleza privada: tienden a repetirse y a extenderse a todos los componentes de la colectividad, en razón del bien (salud, ambiente, habitación, etc.) (Bigliazzi 1998: 1155). Con razón, se sostiene que el interés difuso "es extenso, amplioy pertenece a un número indeterminado de personas, pero no por esto es un interés débil o abstracto; todo lo contrario, se trata de interés cierto", y el hecho de que pertenezca a "todos en general y a nadie en particular" no lo debilita, sino que lo hace "más digno de protección" (Arrarte 1994: 123).

\section{Los principios}

La LGA establece en su título preliminar los siguientes principios:

a) Principio de sostenibilidad (artículo V):

La gestión del ambiente y de sus componentes, así como el ejercicio y la protección de los derechos que establece la presente ley, se sustentan en la integración equilibrada de los aspectos sociales, ambientales y económicos del desarrollo nacional, así como en la satisfacción de las necesidades de las actuales y futuras generaciones.

b) Principio de prevención (artículo VII):

La gestión ambiental tiene como objetivos prioritarios prevenir, vigilar y evitar la degradación ambiental. Cuando no sea posible eliminar las causas que la generan, se adoptan las medidas de mitigación, recuperación, restauración o eventual compensación que correspondan. 
c) Principio precautorio (artículo VII):

Cuando haya peligro de daño grave o irreversible, la falta de certeza absoluta no debe utilizarse como razón para postergar la adopción de medidas eficaces y eficientes para impedir la degradación del ambiente.

d) Principio de internalización de costos (artículo VIII):

Toda persona natural o jurídica, pública o privada, debe asumir el costo de los riesgos o daños que genere sobre el ambiente. El costo de las acciones de prevención, vigilancia, restauración, rehabilitación, reparación y la eventual compensación, relacionados con la protección del ambiente y de sus componentes de los impactos negativos de las actividades humanas debe ser asumido por los causantes de dichos impactos.

e) Principio de responsabilidad ambiental (artículo IX):

El causante de la degradación del ambiente y de sus componentes, sea una persona natural o jurídica, pública o privada, está obligado a adoptar inexcusablemente las medidas para su restauración, rehabilitación o reparación según corresponda o, cuando lo anterior no fuera posible, a compensar en términos ambientales los daños generados, sin perjuicio de otras responsabilidades administrativas, civiles o penales a que hubiera lugar.

f) Principio de equidad (artículo X):

El diseño y la aplicación de las políticas públicas ambientales deben contribuir a erradicar la pobreza y reducir las inequidades sociales y económicas existentes; y al desarrollo económico sostenible de las poblaciones menos favorecidas. En tal sentido, el Estado podrá adoptar, entre otras, políticas o programas de acción afirmativas, entendidas como el conjunto coherente de medidas de carácter temporal dirigidas a corregir la situación de los miembros del grupo al que están destinadas, en un aspecto o varios de su vida social o económica, a fin de alcanzar la equidad efectiva.

g) Principio de gobernanza ambiental (artículo XI):

El diseño y aplicación de las políticas públicas ambientales se rigen por el principio de gobernanza ambiental, que conduce a la armonización de las políticas, instituciones, normas, procedimientos, herramientas e información de manera tal que sea posible la participación efectiva e integrada de los consensos, sobre las base de 
responsabilidades claramente definidas, seguridad jurídica y transparencia.

De todos estos principios, toman particular relevancia el de sostenibilidad y el de precaución. Respecto del primero, autorizada doctrina nacional advierte que "[...] no cabe duda de que nuestra sociedad no pretende - ni puede pretender cuerdamente - preservar una pureza ambiental y paisajística prístina y absoluta a cualquier costo. Por este motivo, no todo daño ambiental es antisocial, sino solo aquel que la sociedad considere excesivo para su grado de conciencia del peligro". ${ }^{1}$

En cuanto al principio de precaución, "[...] se trata de actuar antes de que se produzca un peligro, aunque sea potencial, con el fin de evitar el surgimiento de una situación intrínsecamente peligrosa que sería después extremadamente difícil de afrontar adecuadamente por falta de los necesarios conocimientos científicos y técnicos" (Tucci 2006: 890). En efecto, el artículo 1 de la Ley 29050, del 22 de junio del 2007, que modificó el literal $\mathrm{k}$ del artículo 5 de la Ley Marco del Sistema Nacional de Gestión Ambiental, Ley 28245, del 4 de junio del 2004, se refiere a este principio de la siguiente forma:

Precautorio, de modo que cuando haya indicios razonables de peligro de daño grave o irreversible al ambiente o, a través de este, a la salud, la ausencia de certeza científica no debe utilizarse como razón para no adoptar o postergar la ejecución de medidas eficaces y eficientes destinadas a evitar o reducir dicho peligro. Estas medidas y sus costos son razonables considerando los posibles escenarios que plantee el análisis científico que se vayan produciendo con posterioridad a su adopción. La autoridad que invoca el principio precautorio es responsable de las consecuencias de su aplicación.

Cuando se ignoran los efectos de una actividad o producto, creemos plenamente en la intervención del Estado, sobre la base del principio

1 Siguiendo a Frank Michelman: De Trazegnies (1988: 329). 
precautorio, para asegurar una adecuada protección del medio ambiente y de la salud.

\section{Las responsabilidades formales}

Si bien la LGA contiene una regla general de responsabilidad administrativa (artículo 74) y de responsabilidad social (artículo 78), se entiende que la responsabilidad civil es independiente de la responsabilidad administrativa (artículo 138). Es importante comenzar el análisis de la responsabilidad civil por daño ambiental con el artículo 142:

142.1 Aquel que mediante el uso o aprovechamiento de un bien o de un ejercicio de una actividad pueda producir un daño al medio ambiente, a la calidad de vida de las personas, a la salud humana o al patrimonio, está obligado a asumir los costos que se deriven de las medidas de prevención y mitigación de daño, así como los relativos a la vigilancia y monitoreo de la actividad y de las medidas de prevención y mitigación adoptadas.

142.2 Se denomina daño ambiental a todo menoscabo material que sufre el ambiente y/o alguno de sus componentes, que puede ser causado contraviniendo o no disposición jurídica, y que genera efectos negativos actuales o potenciales.

En materia de intereses difusos, siempre ha sido discutido quién o quiénes tienen legitimidad para obrar. El artículo 143 zanja este problema: “Cualquier persona, natural o jurídica, está legitimada para ejercer la acción a que se refiere la presente ley, contra quienes ocasionen o contribuyen a ocasionar un daño ambiental, de conformidad con lo establecido en el artículo III del Código Procesal Civil".

Es notoria la diferencia de esta regulación con lo preceptuado en el artículo 82 del Código Procesal Civil (en adelante, CPC), el cual -en caso de la defensa de los intereses difusos - le otorga la legitimidad para obrar al Ministerio Público, los gobiernos regionales o locales, las comunidades campesinas o nativas en cuya jurisdicción se produjo el daño ambiental o al patrimonio ambiental, y las asociaciones o instituciones sin fines de lucro que según la ley y criterio del juez (este último, por resolución debidamente motivada) estén legitimadas para 
ello. Incluso a las rondas campesinas que acrediten personería jurídica se les otorga el mismo derecho que a las comunidades campesinas o nativas en los lugares donde estas no existan o no se hayan apersonado a juicio. ¿Qué disposición debe primar? Creemos que no son excluyentes; sic et simpliciter, la LGA ha ampliado la esfera de los sujetos legitimados para obrar. El problema es otro: ¿qué daños va a reclamar la persona individualmente considerada afectada por el ilícito ambiental? $\mathrm{La}$ naturaleza de esta responsabilidad es, evidentemente, objetiva. En efecto, "el contaminador va a sobrellevar el beneficio y los costos de la contaminación, y tiene los incentivos adecuados para maximizar los beneficios netos del uso del terreno" (Epstein 2005: 297). Así lo delimita el artículo 144:

La responsabilidad derivada del uso o aprovechamiento de un bien ambientalmente riesgoso o peligroso o del ejercicio de una actividad ambientalmente riesgosa o peligrosa es objetiva. Esta responsabilidad obliga a reparar los daños ocasionados por el bien o actividad riesgosa, lo que conlleva a asumir los costos contemplados en el artículo 142 precedente, y los que correspondan a una justa y equitativa indemnización; los de la recuperación del ambiente afectado, así como los de ejecución de las medidas necesarias, para mitigar los efectos del daño y evitar que este se vuelva a producir.

Sin embargo, se crean curiosos (¿o ficticios?) espacios de responsabilidad subjetiva en el artículo 145:

La responsabilidad en los casos no considerados en el artículo anterior es subjetiva. Esta responsabilidad solo obliga al agente a asumir los costos derivados de una justa y equitativa indemnización y los de restauración del ambiente afectado en caso de mediar el dolo o culpa. El descargo por falta de dolo o culpa corresponde al agente.

Aunque se establezca, al igual que en el artículo 1969 del Código Civil (en adelante, CC), un supuesto de presunción de responsabilidad subjetiva, nos cuesta, en verdad, imaginar un caso en el que al realizar una actividad en la cual se dañe el ambiente no se incurra - al mismo 
tiempo - en una actividad riesgosa o peligrosa ${ }^{2}$ (veremos hasta dónde llegará la imaginación de algunos abogados). Calificada doctrina italiana, al comentar el artículo 2050 CC italiano (inspiración de nuestro artículo1970CC), afirma quelanaturaleza objetiva deesta responsabilidad “[...] se deberá aplicar a los empresarios, pero no a sus dependientes, encargados del desenvolvimiento de las actividades peligrosas individualmente consideradas: a estos últimos se aplicará la responsabilidad por culpa ( $\mathrm{y}$ en la evaluación de la culpa se tendrá en cuenta el carácter peligroso de la actividad realizada)" (Trimarchi 1967: 280). No estamos de acuerdo: el ejercicio de la actividad riesgosa lo realiza el dependiente, por ello es objetiva; y el principal responde porque aquel es una extensión (longa manu) de este. Distinto es el escenario del artículo 1981 CC: ahí el dependiente está sometido a una responsabilidad subjetiva (su actuar, aunque pequemos con decir lo evidente, no implica el criterio de riesgo: fundamento por excelencia de la responsabilidad objetiva).

En materia de supuestos de ruptura del nexo causal, el artículo 146 establece:

No existirá responsabilidad en los siguientes supuestos: a) Cuando concurran una acción u omisión dolosa de la persona que hubiera sufrido un daño resarcible de acuerdo con esta ley; b) Cuando el daño o el deterioro del medio ambiente tenga su causa exclusiva en un suceso inevitable o irresistible; y c) Cuando el daño o el deterioro del medio ambiente haya sido causado por una acción y omisión no contraria a la normativa aplicable, que haya tenido lugar con el previo consentimiento del perjudicado y con conocimiento por su parte del riesgo que corría de sufrir alguna consecuencia dañosa derivada de tal o cual acción u omisión.

2 En este mismo sentido, Chinchay sostiene: “[...] de todas formas no creemos que el artículo 145 sea peligroso en el sentido de que sería un tanto difícil que los jueces acepten alegaciones de entidades contaminadoras solicitando se resuelva su caso aplicando el criterio de culpa por ejercer actividades no riesgosas ni peligrosas"' (2009: 288). 
Llama la atención que no se haya contemplado el supuesto de hecho de un tercero (aunque podría incluirse en el inciso b, al tratarse de "un suceso inevitable o resistible", o incluso complementarse con los artículos 1972 y 1973 CC, este último, que opera como concausa). Mención aparte merece el inciso c: es cierto que el derecho formalmente válido establece límites y estándares en los cuales está permitido dañar; sin embargo, este dispositivo choca frontalmente con el artículo 142.2, ya que puede haber daño ambiental "contraviniendo o no la disposición jurídica".

No se debe confundir el supuesto del artículo 146.c con el de las cláusulas en las cuales se exonera de responsabilidad extracontractual (o se la limita) al que daña (artículo 1986 CC). Si bien (formalmente) solo serían válidas si obedecen a culpa leve (no por dolo ni culpa inexcusable), ¿acaso no se violan normas de orden público (artículo $\mathrm{V}$ del título preliminar del (C)? En efecto, también merece considerarse este acuerdo por el filtro de constitucionalidad: cuando media la culpa leve, ¿no se debe resarcir un daño al medio ambiente? La respuesta correcta es la negativa: se impone el respeto a la persona humana (artículo 1 Const.) y la propia protección del medio ambiente (artículo 67 Const.) cuando se refiere al "uso sostenible" de los recursos naturales. Por consiguiente, aunque exista "previo consentimiento", no cabe duda de la configuración de una supuesta ruptura del nexo causal ni, mucho menos, estamos frente a un "ejercicio regular de un derecho" (artículo 1971.1 CC).

El derogado Código del Medio Ambiente y los Recursos Naturales, D. Leg. 611, del 7 de octubre de 1990, establecía en su artículo 141: “En las acciones de abuso de derecho que sean interpuestas al amparo del artículo II del título preliminar del Código Civil y se refieran a la tutela de derechos de naturaleza ambiental, las medidas preventivas dictadas para evitar o suprimir el abuso sólo podrán ser apelables en efecto devolutivo". El principio del abuso de derecho sigue vigente y está reconocido por la Constitución (artículo 103) y el CC.

En materia de reparación del daño, el artículo 147 norma:

La reparación del daño ambiental consiste en el restablecimiento de la situación anterior al hecho lesivo al ambiente o sus componentes, y de la indemnización económica del mismo. De no ser técnica ni materialmente posible el restablecimiento, el juez deberá prever la 
realización de otras tareas de recomposición o mejoramiento del ambiente o de los elementos afectados. La indemnización tendrá por destino la realización de acciones que compensen los intereses afectados o que contribuyan a cumplir los objetivos constitucionales respecto del ambiente y los recursos naturales.

¿Qué voces de daño se pueden invocar? La respuesta depende de quién es el que ha interpuesto la demanda. En efecto, aunque hemos visto que hasta las personas individualmente afectadas están legitimadas para pedir una indemnización, tenemos que delimitar qué universo comprendería la pretensión resarcitoria. Con razón, en doctrina se afirma que:

[...] otra cuestión es que el mismo hecho, que causa la degradación ambiental, pueda dar lugar contextualmente a daños injustos a los miembros de la colectividad individualmente considerados, incidiendo en los bienes propios de estos (como la salud, la propiedad, otros derechos de goce). Para tales hipótesis, puede hablarse de daño ambiental sólo en una acepción meramente descriptiva del hecho lesivo y no para indicar las característica de la tutela, que serán aquellas propias del bien lesionado. ${ }^{3}$

Por ello, debemos distinguir:

a) Si se trata del "restablecimiento de la situación anterior al hecho lesivo al ambiente o sus componentes", están legitimados el Ministerio Público, los gobiernos regionales o locales, las comunidades campesinas, nativas o rondas, incluso los directamente dañados, de manera individual o colectiva. Ejemplo: en el caso de un río contaminado, el dañante deberá realizar las labores necesarias para su descontaminación.

b) Si se trata de la "indemnización económica", se presentarían las siguientes variables:

3 Salvi (1998: 82-83); en el mismo sentido: Batá (1996: 158). 
i. Está legitimado aquel que sufrió el daño de manera individual y a quien directamente lo ha afectado. En este sentido, lo ampararía el artículo 1985 CC, es decir, invocará el daño emergente, el lucro cesante, el daño moral y el daño a la persona; incluso los daños futuros, si son debidamente acreditados (Busnelli y Patti 1997: 111). Es evidente que puede asumir la representación otorgada por otras víctimas.

ii. El Ministerio Público, los gobiernos regionales o locales, las comunidades campesinas, nativas o rondas pueden actuar en representación de las víctimas individualmente consideradas.

La legislación peruana no ha incorporado la expresión daños punitivos. Creemos que es momento de dar un paso adelante y asimilar esta categoría indemnizatoria para reforzar la desincentivación de situaciones que perfectamente encajan dentro de lo que se llama el "incumplimiento eficiente". Se ha de tener en cuenta, además, que el monto no debe ir con exclusividad a la víctima individualmente considerada (salvo un porcentaje, para incentivar la práctica de estas acciones), ya que se crearía una distorsión. Sería aconsejable que la mayor parte del monto vaya a un fondo compensatorio para otras víctimas o para realizar acciones preventivas o de monitoreo.

Convenimos plenamente con quien sostiene que la "[...] denominación 'daño punitivo' empleada por la ley, aunque pretende ser una traducción literal de la expresión punitive damages, es equívoca desde el punto de vista conceptual, por lo que nos parece más apropiado designar a la figura jurídica como multa civil por actos desaprensivos" (Moisá 2008: 444). Asimismo, se entiende que los presupuestos para que se configure esta sanción civil pecuniaria "[...] son dos: uno objetivo, la existencia de un daño grave, o de trascendencia social, o de repercusión institucional; y b) otro subjetivo, una conducta dolosamente desaprensiva o antisocial en el sujeto dañador" (Moisá 2008: 445). Aun así, consideramos que deben establecerse parámetros objetivos para determinar este tipo especial de dolo.

Otros temas que han sido omitidos son los relativos a la probanza del nexo causal, del daño ambiental y su cuantificación. En lo que al nexo causal se refiere, sabemos que el análisis causal es dual, vale decir, se debe indagar quién es el responsable (causalidad de hecho) y hasta dónde se es responsable (causalidad jurídica). La doctrina sostiene que "la 
investigación relativa a los perfiles causalísticos se concentraría en la causalidad de hecho: es decir, en el nexo entre la conducta contaminante y el evento que constituiría la saturación" (Somma 1998: 722). Creemos que en este tipo de casos es muy aplicable la teoría de la causalidad probabilística. ${ }^{4}$ Es evidente que la carga probatoria debe recaer en quien está en mejor posición para asumirla.

Un sector de la doctrina italiana afirma que en materia ambiental, una prueba completa y minuciosa del daño es objetivamente imposible, debido a que algunos efectos perjudiciales se evidencian con el transcurso del tiempo o son muy difíciles de probar. Por lo tanto, ¿qué criterios debe tener en cuenta el juez a efectos de cuantificar el daño ambiental? En legislación comparada, en Italia, el inciso 6 del artículo 18 de la Ley 349/1986, del 8 de julio de 1986, ley que instituye el Ministerio del Ambiente y normas en materia de daño ambiental, establece: “El juez cuando no sea posible una precisa cuantificación del daño determina el monto en vía equitativa, teniendo en cuenta la gravedad de la culpa individual, el costo necesario para la reparación y el provecho obtenido por el transgresor como consecuencia de su comportamiento lesivo de los bienes ambientales".

Estos criterios obedecen tanto a la finalidad reparadora como a la sancionadora del daño (Di Majo 2001: 217). Por otro lado, se afirma que “[...] la evaluación equitativa deberá tener en cuenta los parámetros expresamente indicados en la ley, pero deberá además hacer referencia a la entidad -aunque no sea exactamente determinable en su monto preciso - del daño producido y deberá, en fin, tener presentes los fines que la ley se propone y en particular la función asignada al resarcimiento del daño" (Busnelli y Patti 1997: 100). Las normas están ya dadas. Ahora, las preguntas son: ¿se cumplen? ¿Las aplican los operadores jurídicos?

\section{El caso}

El 2 de junio del 2000, un camión de la compañía Ransa derramó 151 kilos de mercurio en las localidades de Choten, San Juan, La Calera, El Tingo, Magdalena y San Sebastián de Choropampa; en esta última se

4 Permítaseme remitir a Espinoza (2007: 176, 189-193). 
dio el más alto nivel de contaminación (investigaciones posteriores detectaron 16 puntos de derrame en esa zona). Producto de ello, centenares de personas tuvieron contacto con la sustancia, que era de propiedad de minera Yanacocha. En efecto, los pobladores que estaban en las inmediaciones recogieron parte del mercurio derramado, ignorando que se trataba de una sustancia tóxica. A las pocas horas, todo el pueblo había sido atraído por la noticia de la presencia de este mineral con particular forma y brillo. El recojo se prolongó hasta las primeras horas del día siguiente. En las demandas que se interpusieron se noticia que los propios representantes de Yanacocha contrataron a los pobladores para recoger el mercurio a cambio de $S / .15$, más el regalo de la escoba utilizada para ese fin (se sostiene que, al estar contaminada, intoxicó a los ocupantes de las casas en donde se guardaba ese útil de limpieza).

Otra afirmación que se hace en las demandas es que en la posta médica y en el hospital de esa ciudad, más de 250 casos habían sido tratados con quelantes (penicilamina), medicamentos que la Sociedad Médica de Estados Unidos dispuso retirar del mercado debido a su alto grado de complicaciones y los riesgos de su aplicación en pacientes sometidos a intoxicaciones agudas. Se afirma que la misma Yanacocha había distribuido estos medicamentos con la finalidad de disminuir de modo rápido los niveles clínicos de intoxicación por mercurio en la sangre y la orina, a pesar de que tienden a producir una mayor absorción de los tóxicos en el torrente sanguíneo y los órganos blandos, como riñones, corazón, hígado, ojos y pulmones.

Vamos a centrarnos en la demanda que interponen, con fecha 6 de mayo del 2002, Marcial Alvitrez Tuesta y otras dieciséis personas contra Yanacocha, en donde se solicita, como pretensión principal, la suma de US\$4.200.000 por concepto de responsabilidad civil extracontractual, es decir, daño material (daño bioambiental y daño a la salud personal) y daño moral. Como pretensiones acumuladas, se formulan las siguientes:

a. Pago de un seguro médico y un seguro de vida a favor de cada uno de los recurrentes y de sus hijos por una suma no menor de US $\$ 100.000$ por el lapso de 30 años, con cobertura a todo riesgo, incluyendo enfermedades oncológicas.

b. Descontaminación completa y de modo óptimo de las viviendas, de los materiales químicos que han ocasionado daños. 
c. Pago de intereses legales, costas y costos, así como de multas en caso de oposición.

Se afirma que cuando el vapor del mercurio interior en las casas es superior a 0,003 $\mathrm{mg} \mathrm{hg} / \mathrm{m}^{3}$ (límite sobrepasado en extremo), la acción aconsejada es la evacuación inmediata de los ocupantes y la limpieza inmediata de la casa, lo que no sucedió. Por tanto, a los miembros de Yanachocha y a los directivos de las entidades públicas a cargo del control de la intoxicación se les imputó una conducta dolosa. A su vez, se invocaron como fundamentos de derecho los artículos 1970 y 1985 CC, el Texto Único Ordenado (TUO) de la Ley de Minería y el Código del Medio Ambiente y los Recursos Naturales.

El Juzgado Mixto del Módulo Básico de Santa Apolonia, con resolución 1 del 26 de mayo del 2005, admitió a trámite la demanda. Minera Yanacocha, en el plazo oportuno, interpuso las siguientes excepciones:

a. Conclusión del proceso, por transacción, respecto de cinco codemandantes (artículo 446.10 CPC).

b. Falta de legitimidad para obrar pasiva de la minera (porque el transporte lo hizo Ransa y no Yanacocha).

c. Falta de legitimidad para obrar activa de dos de los codemandantes, pues no habían nacido al momento del daño.

Con resolución 3 del 20 de junio del 2002, el mencionado Juzgado Mixto corre traslado de las excepciones. Con fecha 19 de enero del 2004 se celebra la audiencia de saneamiento procesal, en la que ya intervienen Ransa y el chofer de un camión: Arturo Blanco Zar. Ransa interpone las excepciones de falta de legitimidad para obrar del demandado, de prescripción extintiva, de falta de legitimidad para obrar de los demandantes, de conclusión del proceso por transacción y de incapacidad del demandante. Blanco interpone las excepciones de prescripción extintiva, de conclusión del proceso por transacción y de legitimidad para obrar de los codemandantes en relación con la pretensión indemnizatoria por el daño ambiental.

En esa resolución se desestima la excepción de transacción por las siguientes consideraciones: 
[...] Que, en el campo civil, las transacciones se encuentran reguladas tanto por la normatividad sustantiva, comoen la adjetiva, encontrándose las primeras entre los artículos 1302 al 1312 del Código Civil, en tanto que en el campo procesal, se encuentra regulado por las normas previstas en los artículos 334, al 339, 446 y 453 del Código Procesal Civil, resultando necesario resaltar que en materia de transacción la normativa civil es supletoria de la procesal por disposición expresa de lo precisado en el artículo 338 de la norma adjetiva.

[...] Que, en este caso especifico estamos analizando, entre otros, las transacciones formuladas por sus padres y relacionadas a los menores (en ese entonces) Guillermo Dobbertin Espino y Enrique Alejandro Dobbertin Espino, en los cuales los padres no han contado con la autorización judicial para hacerlo. En consecuencia, se ha incumplido con lo establecido en el artículo 448, inciso 3, según el cual se necesita que los padres previamente cuenten con una autorización judicial, por lo que estas carecen de valor legal; no resultando amparable la excepción propuesta con relación a los mismos, por lo que debe desestimarse la excepción en este último extremo, de la misma manera se ha celebrado transacciones con los mayores María Isabel Gutiérrez Chiclote, Juan Terrones Leyva y Aurora Tuesta Saldaña, con relación a los cuales resulta necesario tener en cuenta lo establecido en los artículos 446 y 453 del ordenamiento procesal, en cuya norma última se precisa que son fundadas las excepciones, entre otras, las de conclusión del proceso por transacción cuando se inicie un proceso idéntico a otro, en suma, se requiere que la transacción haya sido homologada en otro proceso anterior, vale decir que una transacción extrajudicial se convierta en judicial, raciocinio al que se llega haciendo una interpretación sistemática de las normas anteriormente señaladas como el artículo 339 del mismo ordenamiento legal (las cursivas son nuestras).

También se desestima la excepción de falta de legitimidad para obrar pasiva, interpuesta por Yanacocha, porque:

Debe tenerse en cuenta lo establecido en el artículo cinco del Decreto Supremo cero dieciséis guión, noventa y tres guión EM, el cual aprueba el Reglamento para la Protección Ambiental de la Actividad Minero Metalúrgica, que obra a folios ciento ocho (cuaderno de excepciones I) y que expresamente señala: "El titular de la actividad minerometalúrgica es responsable por las emisiones, vertimientos y disposición 
de los deshechos al medio ambiente que se produzcan como resultado de los procesos efectuados en sus instalaciones". En este orden de ideas, existe plena identidad entre este demandado como sujeto de la relación sustantiva y su condición de titular de la relación procesal; que con relación a Ransa como agente de transporte, su actividad de por sí es riesgosa. En todo caso, se deberá evaluar la prueba final del proceso, para determinar su responsabilidad o irresponsabilidad en el hecho dañoso (las cursivas son nuestras).

Se ampara la excepción de falta de legitimidad activa de dos de los codemandantes, que no habían nacido al momento de producirse el derrame, argumentando que "la persona humana es sujeto de derechos a partir de su nacimiento". Se debe precisar que, en este caso, los nacimientos fueron después de un año dos meses y de un año siete meses, respectivamente. Los codemandantes ni siquiera habían sido concebidos al momento del daño. Sin embargo, si se acreditaba que las madres habían sufrido los efectos de la contaminación que, a su vez, habían transmitido a sus hijos -no obstante la concepción fuera después del derrame- , esta excepción debería haberse desestimado.

Respecto de la excepción de prescripción interpuesta por Ransa y el chofer, se afirma:

Que, como lo establece reiterada jurisprudencia, como la establecida en la casación número dos mil ciento catorce guión noventa y ocho transcrita en "El Código Civil a través de la Jurisprudencia Casatoria" -Asociación No hay Derecho- Ediciones Legales. Primera Edición, dos mil dos - página seiscientos diez: "El plazo de prescripción para demandar la indemnización por responsabilidad extracontractual derivada de un hecho punible se suspende con la expedición en la vía penal del auto apertorio de instrucción por los mismos hechos del cual se deriva la acción civil, a tenor de lo dispuesto en el artículo 100 del Código Penal, que establece que la acción civil derivada del hecho punible no se extingue mientras subsista la acción penal", por lo que debe desestimarse la excepción señalada (las cursivas son nuestras).

Aunque exista o no exista un proceso penal en trámite, al haberse interpuesto la demanda contra Yanacocha, que sería responsable 
solidaria con Ransa y el chofer (artículos 1970, 1981 y 1983 CC), también se interrumpe el plazo prescriptorio respecto de estos dos últimos codemandados. En efecto, el artículo 1196 CC establece: "Los actos mediante los cuales el acreedor interrumpe la prescripción contra uno de los deudores solidarios, o uno de los acreedores solidarios interrumpe la prescripción contra el deudor común, surten efecto respecto de los demás deudores o acreedores".

No fue amparada la excepción de falta de legitimidad para obrar de los demandantes, que se basó en la argumentación de que no se adjuntaron a la demanda las constancias o certificados médicos que acrediten el supuesto causado, por cuanto el incumplimiento de esta carga no es un sustento para ello. Sucedió lo mismo respecto de quien alegó que no anexó el documento de identidad. Se amparó la excepción de falta de legitimidad para obrar respecto de la pretensión indemnizatoria de daño ambiental; ello en atención al artículo 82 CPC:

Interés difuso es aquel cuya titularidad corresponde a un conjunto indeterminado de personas respecto de bienes de inestimable valor patrimonial, tales como el medio ambiente o el patrimonio cultural o histórico o del consumidor. Pueden promover o intervenir en este proceso; el Ministerio Público, los gobiernos regionales, los gobiernos locales, las comunidades campesinas y/o asociaciones o instituciones sin fines de lucro que según la ley y criterio del juez, este último por resolución debidamente motivada, estén legitimadas para ello. Las rondas campesinas que acrediten personería jurídica, tienen el mismo derecho que las comunidades campesinas o las comunidades nativas en los lugares donde estas no existan o no se hayan apersonado al juicio (las cursivas son nuestras).

$\mathrm{Al}$ parecer, el juez se olvidó del artículo 3 del título preliminar del D. Leg. 613, Código del Medio Ambiente y Recursos Naturales, vigente desde entonces, que establecía: "Toda persona tiene derecho a exigir una acción rápida y efectiva ante la justicia en defensa del medio ambiente y de los recursos naturales y culturales. Se pueden interponer acciones aun en los casos en que no se afecte el interés económico del demandante o denunciante" (las cursivas son nuestras).

Compartimos plenamente la posición de quien sostiene que "[...] si bien el Código Procesal Civil no niega la posibilidad de otorgarle legitimidad para obrar activa extraordinaria a cualquier persona para 
defender el derecho [al] ambiente, las normas jurídicas ambientales sí contemplan esta posibilidad y la conceden de manera contundente" (Alonzo 2009: 314-315). Yanachocha apela respecto de estas decisiones. La Sala Superior de Justicia de Cajamarca, con resolución 12, del 28 de marzo del 2006, decide sobre la excepción de falta de legitimidad para obrar de la minera, que:

Debe señalarse que esta defensa formal está referida a la legitimación con la que debe contar en este caso, la excepcionante para ser emplazada, debiendo tenerse en cuenta que no se debe acreditar fehacientemente su calidad de titular de la relación sustancial discutida. Que, en el presente caso se advierte que el factor de imputación de la responsabilidad extracontractual en la demanda se ha referido al transporte de mercurio, actividad a la que no se dedica la empresa emplazada, por tanto la excepción resulta fundada. [...] Que, atendiendo a que en el presente proceso ya se encuentran comprendidos Ransa Comercial Sociedad Anónima y Esteban Arturo Blanco Bar, quienes efectivamente forman parte de la relación jurídica procesal, en su condición de litisconsortes necesarios pasivos, ya no resulta necesario proceder conforme lo dispone el artículo 451 inciso 4 del Código Procesal Civil, y ello en virtud al principio de economía y celeridad procesal al determinarse que la relación jurídico procesal ya se encuentra debidamente definida (las cursivas son nuestras).

¿En función de la economía y celeridad de quién están razonando estos vocales? No se entiende por qué se emite un juicio de responsabilidad (que se tendría que ver durante el proceso, pues se trata de un tema de fondo) a efectos de pronunciarse sobre la relación jurídica procesal. Por ello, no se puede determinar a priori la exclusión de Yanacocha amparándose en una excepción que tiene carácter formal. Se confunde (o se quiere confundir) gruesamente un análisis causal con una excepción procesal, que tiene escenarios y funciones diversas. Peor aún, se olvida que en la demanda no solo se reclama a Yanacocha por el transporte, sino por el contrato de "recuperación" del mercurio con los campesinos y el suministro de medicamentos. Sin embargo, se cuenta con un voto discordante:

Se debe tener en cuenta que el artículo cuarto del título preliminar del Código Procesal Civil señala que el accionante invocará interés para 
obrar, queriendo con ello decir que basta la imputación del demandante de considerarse y considerar que su demandado satisfaga su pretensión, para que dicha condición sea satisfecha, no siendo necesario que exista fundabilidad en su demanda, pues ello será visto en las sentencias.

Por si eso fuera poco, la construcción interpretativa de los vocales no llega a tener límites cuando, a propósito de la excepción de falta de legitimidad para obrar y de prescripción de Ransa, se razona que:

De precisarse que conforme a lo expuesto anteriormente y al hecho que en el presente proceso la parte demandante ha manifestado tener derecho a la pretensión reclamada y que la indicada empresa (Ransa) es responsable por haber transportado el mercurio, actividad que ella misma reconoce haber efectuado, debiendo tener en cuenta que la obligación del transportista no solo era el de transportar el mercurio propiamente dicho, sino que dicho transporte debió hacerse con seguridad y cuidado, por lo que dicha excepción en cuanto a esta parte debe ser declarada infundada: [...] Que, con respecto a la Excepción de Prescripción Extintiva de la Acción, el colegiado precisa lo siguiente: a) conforme lo dispone el (art.) 1983 del Código Civil: "si son varios los responsables del daño, responderán solidariamente", y en este sentido Aníbal Torres Vásquez, en el Código Civil, página novecientos sesenticuatro, Sexta Edición dos mil dos, Bogotá-Colombia, señala "el artículo mil novecientos ochentitrés instituye la responsabilidad solidaria entre los coautores de un acto ilícito por la indemnización del daño. Hay coautoría cuando concurren las acciones de dos o más personas en el mismo acto dañino [...] en base a la solidaridad, frente a la víctima todos son responsables por igual de la totalidad de la obligación [...] el artículo mil novecientos ochentitrés regula la concurrencia de los responsables subjetivos (a título de culpa o falta) [...]"; b) De lo expuesto aquí se aprecia que la responsabilidad es solidaria y siendo ella nacida del mandato legal, que es una de las fuentes por medio de las cuales nace y que la solidaridad legal no se presume, y que esta fuente legal es el artículo 1983 del Código Civil; c) De allí que el artículo 1996 del Código Civil, señala en el inciso tres que: se interrumpe la prescripción por "[...] citación con la demanda [...]" y como queda establecido en autos, con el cargo de notificación obrante a folios seiscientos sesenta y cuatro, la parte demandante 
emplazó a la demandada Minera Yanacocha Sociedad de Responsabilidad Limitada, y por tanto interrumpió el plazo prescriptorio, no solo para dicha parte procesal, sino que existiendo solidaridad legal pasiva, interrumpió la prescripción también para los demás deudores, ya que la interrupción de la prescripción respecto de uno de los deudores solidarios, surte efecto respecto de los otros, y la interrupción de la prescripción emanada de uno de los acreedores solidarios respecto del deudor común, aprovecha a los demás coacreedores; d) Por ello y al haber sido emplazada Minera Yanacocha Sociedad de Responsabilidad Limitada, dentro del plazo establecido en el numeral 4 del artículo 2001 del Código Civil, se ha interrumpido la prescripción en cuanto a ella, y sus co-demandados solidarios, y por esas razones, la Excepción de Prescripción Extintiva de la Acción debe ser desestimada (las cursivas son nuestras).

¡De Ripley! Violentando el más elemental sentido de coherencia, se excluye a Yanacocha de la relación procesal porque (según los vocales) no forma parte de la relación material, pero (a efectos de incluir a Ransa en el proceso) se sostiene que Yanacocha y Ransa json deudores solidarios! Como no podía ser de otra manera, se interpone recurso de casación contra esa resolución, y la Sala Civil Transitoria de la Corte de Justicia de la República, con resolución del 17 de octubre del 2006 (Cas. 2162-2006 Cajamarca), lo declara procedente. Por último, con resolución del 28 de mayo del 2007 (publicada el 31 de mayo del 2008), la Corte Suprema ordena que la sala de procedencia emita una nueva resolución pronunciándose sobre las excepciones con arreglo a derecho. Respecto de la excepción de falta de legitimidad para obrar pasiva de Yanacocha, se afirma que:

La recurrente señala, que al resolverse la excepción de falta de legitimidad para obrar de la codemandada Minera Yanacocha, se ha infringido el debido proceso por los siguientes puntos: i) Que la responsabilidad civil denunciada en la codemandada, empresa Minera Yanacocha, no se ha atribuido al transporte de mercurio, sino a la contaminación y daño sufrido por los demandantes, la misma que deriva de un bien de propiedad de la demandada, y además dicho daño se ha ocasionado por responsabilidad de la misma, en tal sentido, la relación sustantiva, esencialmente se ha establecido y existe con la empresa Minera Yanacocha, por lo que resulta incorrecto concluir que 
la citada empresa no cuenta con legitimidad para obrar pasiva; y ii) Que, respecto al aludido medio de defensa no se ha realizado una adecuada ni correcta fundamentación ni valoración del proceso, en tal sentido - refiere - que la decisión impugnada no ha generado eficacia ni validez, infringiéndose lo previsto en el artículo ciento veintidós inciso tercero del Código Procesal Civil; [...] los citados actores imputan responsabilidad a la demandada Minera Yanacocha Sociedad de Responsabilidad Limitada, propietaria del mercurio: i) por haber sido aquella quien propició e incrementó los niveles de intoxicación al proponer a los pobladores la compra del mercurio que fuera derramado por la denunciada civil Ransa Comercial Sociedad Anónima durante su transporte, con lo que se expuso a los citados riesgos a los que se exponían con la manipulación del material contaminante, ii) por no haber informado a los pobladores los riesgos a los que se exponían con la manipulación del mercurio; [...] al resolver una excepción de falta de legitimidad para obrar no debe decidir la justicia de la pretensión ni el fondo de la litis, ni mucho menos si el demandado es la persona obligada en la relación sustantiva controvertida en el proceso, ya que estos aspectos de la pretensión deben ser objeto de pronunciamiento en la sentencia, mediante el respectivo juicio de fundabilidad y luego de haberse desarrollado la actividad probatoria sobre los hechos controvertidos en el principal; [...] Que, en ese sentido, cuando la Sala revisora ampara la excepción de la falta de legitimidad para obrar de la parte demandada, deducida por Minera Yanacocha Sociedad de Responsabilidad Limitada, bajo el único argumento de que aquella no transportó el material contaminante que ocasionó el daño y que, por tanto, no le es atribuible responsabilidad alguna, arriba a una conclusión equivocada, toda vez que está juzgando un aspecto del fondo de la litis, y que la codemandada no estaría obligada a indemnizar el daño, aspecto que deber ser objeto de pronunciamiento al momento de expedir sentencia, y no al resolver una excepción en la cual el Colegiado Superior sólo debía verificar si la citada empresa minera era o no la propietaria del mercurio que ocasionó los daños, en atención a los cargos que se formulan en la demanda: [...] Que, por consiguiente, se verifica en autos que los fundamentos fácticos que amparan el apartamiento del proceso de la empresa Minera Yanacocha Sociedad de Responsabilidad Limitada constituyen argumentos de fondo que no corresponden al estadío procesal del saneamiento, por lo que la resolución recurrida es nula en ese extremo, al contravenir lo dispuesto en el inciso tercero del artículo ciento veintidós del Código Procesal Civil, pues no se ajusta al mérito de lo actuado ni a derecho; en ese 
sentido, la denuncia procesal a que se refiere el acápite b.2 referida a la excepción de falta de legitimidad para obrar de Minera Yanacocha del numeral I) de los fundamentos del recurso de casación interpuesto por Marcial Alvitrez Tuesta resulta fundada [...] en el cuarto considerando de la recurrida, aplicando criterios que corresponden a una resolución sobre el fondo de la cuestión controvertida, refiere Minera Yanacocha Sociedad de Responsabilidad Limitada no es parte de la relación jurídica procesal, por no ser autora del daño, lo que importa una transgresión de lo regulado en el inciso sexto del artículo cincuenta del Código Procesal Civil que establece que el juez debe fundamentar los autos y las sentencias, bajo sanción de nulidad, respetando los principios de jerarquía de normas y el de congruencia, por tanto, este extremo del recurso también debe ser amparado (las cursivas son nuestras).

En el voto singular, se sostiene:

$\mathrm{Al}$ analizar el juzgador los hechos, a fin de determinar la legitimidad para obrar de Minera Yanacocha Sociedad de Responsabilidad Limitada, se limitó a apreciar únicamente los fundamentos de defensa de esta, obviando los fundamentos expuestos por la parte demandante, dando lugar así a una motivación aparente, pues de sus considerandos no se presentan elementos fácticos y jurídicos necesarios que justifiquen la razonabilidad de la decisión, por lo que se encuentra incursa en la causal de nulidad procesal prevista en el inciso sexto del artículo cincuenta e inciso tercero del artículo ciento veintidós del Código Procesal Civil, en donde el colegiado superior tiene la obligación no solo de presentar una debida motivación en los hechos y el derecho, de acuerdo al mérito de lo actuado, sino también debe apreciar las implicancias de la solidaridad en la obligación que ha declarado, respecto a la situación de los demandados Ransa Comercial Sociedad Anónima y Esteban Arturo Blanco Bar, a fin de evitar una contradicción interna en la decisión.

Estas decisiones motivan dos reflexiones:

a) Se están confundiendo, en lo que respecta a intereses difusos, quién tiene legitimidad para obrar en materia de daño ambiental, y el 
alcance de las pretensiones del justiciable. El ordenamiento jurídico amparaba y ampara (primera parte del artículo IV del título preliminar de la LGA) a los dañados, individualmente considerados, para accionar a fin de que el juez tome las medidas solicitadas en la citada demanda. La segunda parte del artículo IV del título preliminar de la LGA es clara al respecto: "Se puede interponer acciones legales aun en los casos en que no se afecte el interés económico del accionante. El interés moral legitima la acción aun cuando no se refiera directamente al accionante o a su familia".

b) Tanto Yanacocha como Ransa son responsables solidarios del transporte de mercurio, actividad, por cierto, peligrosa. El hecho de que Ransa haya actuado por encargo de Yanacocha no exime de responsabilidad a la minera. El transportista ha actuado, en este caso, como una longa manu de la minera. Como se advirtió, son aplicables los artículos 1970, 1981 y 1983 CC.

\section{La transacción entendida por nuestros jueces: la controversial sentencia del pleno casatorio civil de la Corte Suprema de Justicia de la República del 22 de febrero del 2008 (Casación 1465-2007-Cajamarca)}

Cierto precedente jurisprudencial tiene un concepto exótico de la transacción. Debido a las lluvias torrenciales que ocasionaron el desembalse de los relaves mineros, así como daños a unas tierras adyacentes, la compañía minera celebró transacciones con los titulares de estas, entre ellos, una persona que afirmó ser la única heredera de una de dichas tierras (que acreditó S/.150 en daños). Sin embargo, después aparecieron dos hermanos más, que, junto con la hermana que había celebrado la transacción, demandaron a la empresa minera por US\$200.000.000. En primera instancia, con resolución del 16 de enero de 1997, el Vigésimo Quinto Juzgado Especializado en lo Civil de Lima declaró infundada la demanda por considerar las lluvias como un caso fortuito. En segunda instancia, la Tercera Sala Civil de la Corte Superior de Lima, con resolución número seis, revocó la sentencia apelada y declaró fundada en parte la demanda, señalando el monto indemnizatorio para cada uno de los demandantes en tres mil nuevos soles, más intereses legales, "debiendo descontar a la co-demandante [...] la suma ya recibida, considerándose como pago a cuenta". Ello evidencia un mayúsculo desconocimiento del carácter de cosa juzgada de la transacción, regulado en el artículo 1302 CC in fine. 
Mediante sentencia del pleno casatorio civil de la Corte Suprema de Justicia de la República del 22 de febrero del 2008 (Casación 1465-2007-Cajamarca), se ha declarado que el siguiente precedente vinculante constituye doctrina jurisprudencial:

La transacción extrajudicial no homologada judicialmente puede ser opuesta como excepción procesal conforme a lo regulado por el inciso 10 del artículo 446 e inciso 4 del artículo 453 del Código Procesal Civil, por interpretación sistemática de dichas normas con las que contiene el Código Civil sobre la transacción. Entendiéndose que las transacciones extrajudiciales homologadas por el juez se tramitan de acuerdo a las reglas del Código Procesal Civil, al tener regulación expresa. Ocurriendo lo mismo en cuanto a las transacciones celebradas con relación a derechos de menores de edad, las mismas que deben ser autorizadas por el juez competente conforme a ley [voto en mayoría].

Han transcurrido quince años para que el pleno de la Corte Suprema saque a la luz su primera doctrina jurisprudencial. Sin embargo, esta decisión es muy discutible; prueba de ello es que cuenta con el siguiente voto en minoría:

1. Como se previene en el Art. [453], resulta procedente la excepción de conclusión del proceso por transacción si concurren los dos siguientes requisitos: a) cuando se inicia un proceso idéntico a otro anterior; y b) que el primer proceso idéntico haya concluido por transacción judicial homologada por el juez que conoce el proceso. En consecuencia, la procedencia de la excepción indicada importa necesariamente la existencia de dos procesos idénticos, de tal modo que la transacción extrajudicial alegada por la parte emplazada, al no haber sido celebrada dentro de un proceso, no puede configurar un supuesto de proceso idéntico y, en tal virtud, no puede sustentar válidamente la excepción de conclusión del proceso de transacción.

2. Si el demandado opone la transacción extrajudicial, debe hacerlo en el escrito de contestación de la demanda y en calidad de defensa del fondo, alegando la extinción de la obligación demandada por efecto 
de aquella, para que el juez se pronuncie sobre esta defensa material en la sentencia.

3. Desde que en las defensas de fondo se discute el derecho sustancial, es en la sentencia donde podrá definirse si la transacción extrajudicial extinguió, total o parcialmente, la obligación que se reclama en la demanda.

4. Para el patrocinio de intereses difusos en un proceso civil, únicamente tienen legitimidad para obrar, activa y extraordinaria, las instituciones y comunidades a que se refiere el Art. 82, por cuanto es una colectividad la titular de los intereses o derechos transpersonales y no una persona individualmente considerada.

5. Si bien, cuando se declara fundado el recurso de casación por una causal procesal (error in procedendo) se debe reenviar la causa a la instancia pertinente para que el juzgador subsane el vicio procesal y emita una nueva decisión, a tenor de lo dispuesto en el Art. 396, sin embargo, se advierte un vacío normativo para el supuesto de que en sede casatoria se ampare o desampare una de las excepciones previstas en el Art. 446 del mismo cuerpo legal o una defensa previa; ante tal vacío, debe integrarse la norma procesal aplicando los principios de dirección, economía y celeridad procesal y procederse a emitir un procedimiento en sede de instancia sobre la procedibilidad y fundabilidad de las excepciones y defensas previas.

Nos inclinamos por el voto en minoría. No entendemos a qué interpretación sistemática se refiere el voto de la mayoría: el artículo 446.10 CPC claramente establece que solo se puede proponer, entre otras, la excepción de "conclusión del proceso por conciliación y transacción", y el artículo 453.4 CPC, que "Son fundadas las excepciones de litispendencia, cosa juzgada, desistimiento de la pretensión o conclusión del proceso por conciliación o transacción, respectivamente, cuando se inicia un proceso idéntico a otro [...] en que las partes conciliaron o transigieron". Sin mucho esfuerzo, se comprende que el legislador está haciendo alusión a la transacción judicial; de otra manera, no se entiende la conclusión de un proceso por transacción ni la alusión a un proceso idéntico a otro.

La pretendida "santidad" de la cosa juzgada que se le quiere dar a la transacción se refiere a la de tipo judicial. Para ello, hay que interpretar 
"sistemáticamente" el artículo 337 CPC. ${ }^{5}$ La transacción extrajudicial es un contrato que puede ser pasible de invalidez (nulidad o anulabilidad, según sea el caso) o de ineficacia; es un contrasentido darle el carácter de cosa juzgada. Los vocales de la Corte Suprema no han debido olvidar que, como cualquier operador jurídico que decide conflictos, no solo se limitan a hacer un control de la legalidad del sistema, sino también deben tener en cuenta la eficacia social y económica de sus decisiones. Al admitir que las posiciones del voto de la mayoría y el de la minoría constituyen argumentaciones razonables, se ha tenido la opción de decidir a favor de una minera o de unos campesinos, con el agravante de que si se da la razón a los campesinos, la minera puede ejercer sus argumentos de defensa durante el proceso, mientras que (como se hizo) al darle la razón a la minera, se le excluye esta posibilidad a los campesinos demandantes. ¿Quién pierde verdaderamente en este proceso? En puridad, al celebrarse las transacciones, la situación de asimetría informativa respecto de la nocividad de la intoxicación por el mercurio, entre la minera y los campesinos, es notoria. La voluntad de estos últimos ha sido viciada, por lo cual los representantes de la minera han incurrido en dolo omisivo (artículo 212 CC).

Si bien es cierto que un sector de la doctrina se ha adherido a la posición del voto de la mayoría, la comunidad jurídica ha manifestado su rotunda crítica: se pone de relieve "el abuso en la libertad de estipulación" (Morales 2008: 56) por parte de la minera. El pleno casatorio consideró que las normas (inciso 10 del artículo 446 CPC, y aquellas con las que es interpretado de manera sistemática) eran las referidas a la transacción que se encuentran en el Código Civil, específicamente el artículo 1302 (considerando 37); no obstante, como parece ser obvio, ni dicha norma ni ninguna otra del Código Civil establecen que las transacciones extrajudiciales pueden ser opuestas como excepciones. Por lo tanto, ¿ante qué clase de interpretación sistemática estamos? De la norma que establece que la transacción tiene como finalidad acabar con una controversia (lo cual no es puesto en duda por nadie) no puede derivarse el momento en que dicha transacción puede ser opuesta procesalmente (Zela 2008: 68). Incluso, no faltan quienes afirman que

5 El cual afirma que "la transacción que pone fin al proceso tiene la autoridad de cosa juzgada". 
la Sala Plena de la Corte Suprema no es un órgano jurisdiccional, sino que tiene funciones meramente administrativas, como lo establece el artículo 80 de la Ley Orgánica del Poder Judicial. ${ }^{6}$ En este orden de ideas, "[...] los derechos que se vulneran es el del juez natural, pues la casación es definida por un órgano ajeno a la Sala Civil permanente de la Corte Suprema; se tolera, además, que se avoque la Sala Plena a la causa en giro y que interfiera en la decisión final, así como que delibere y defina la casación un órgano de gestión administrativa que no ejerce función jurisdiccional". ${ }^{7}$

Por otro lado, se afirma que la invocación de la "aplicación del principio de economía procesal" al formalismo en el proceso civil, es suficiente para atentar contra las normas procesales imperativas, cuando ni la voluntad ni la decisión del juez deben dejarlas de lado" (Arriola 2008: 105). Se advierte que la transacción, siendo un contrato, no goza de la característica de la inmutabilidad de la cosa juzgada, sino más bien puede hacerse objeto de nulidad o anulabilidad (Obando 2007: 107), y que la posición correcta se encuentra "en la interpretación sistemática de los artículos 446 numeral 10 y 453 del CPC, los cuales solamente admiten que la transacción sea opuesta cuando se trate de una transacción judicial. Además, la transacción judicial no es inmutable" (Obando 2007: 118).

6 Ariano (2007: 11); también: Ledesma (2008: 73).

7 Muestra de que el vocal ponente del voto de la mayoría, Vásquez Vejarano, fue autor de sendos votos singulares anteriores... jen sentido contrario! (Ledesma 2008: 73). 


\section{Bibliografía}

ALPA, Guido (2001). Responsabilidad civil y daño. Lineamientos y cuestiones. Lima: Gaceta Jurídica.

ALONZO CHÁVEZ, Henry (2009). "Análisis y comentarios al primer pleno casatorio en materia civil". Ius Doctrina \& Práctica 8.

ARIANO DEHO, Eugenia (2007). “La primera aplicación del artículo 400 del Código Procesal Civil”. La Ley. Año 1, núm. 1.

ARRARTE ARISNABARRETA, Ana (1994). “La defensa procesal de los intereses difusos". Ius et Praxis 24.

ARRIOLA ESPINO, Marcela (2008). ¿Qué podemos decir a propósito del Primer Casatorio Civil? Jus Jurisprudencia 5.

BATÁ, Antonella (1996). "La cassazione e il danno ambientale". Danno e responsabilitá. Milán: IPSOA.

BIGLIAZZI GERI, Lina (1998). Rapportii giuridici e dinamiche sociali: príncipe, norme, interessi emergent: scritti giuridici. Milán: Giuffré.

BUSNELLI, Francesco y Salvatore PATTI (1997). Danno e responsabilitá civile. $2 .^{a}$ edición. Turín: Giappichelli.

BUSTAMANTE ALSINA, Jorge (1997). Teoría general de la responsabilidad civil. 9. ${ }^{\mathrm{a}}$ edición. Buenos Aires: Abeledo-Perrot.

CHINCHAY TUESTA, Ady (2009). “'Subjetivizando la objetividad? La responsabilidad civil por daños al medio ambiente". Revista Jurídica del Perú 98.

DE TRAZEGNIES GRANDA, Fernando (1988). La responsabilidad extracontractual. Volumen IV, tomo II. Lima: Fondo Editorial de la Pontificia Universidad Católica del Perú.

DI MAJO, Adolfo (2001). La tutela civile dei diritti. 3. ${ }^{a}$ edición. Milán: Giuffré.

EPSTEIN, Richard (2005). Reglas simples para un mundo complejo. Lima: Fondo Editorial de la Pontificia Universidad Católica del Perú/ Ius et Veritas.

ESPINOZA ESPINOZA, Juan (2005). Los principios contenidos en el título preliminar del Código Civil peruano de 1984. Análisis doctrinario, legislativo y jurisprudencial. 2. ${ }^{\text {a }}$ edición. Lima: Fondo Editorial de la Pontificia 
Universidad Católica del Perú.

ESPINOZA ESPINOZA, Juan (2007). Derecho de la responsabilidad civil. 5. ${ }^{\mathrm{a}}$ edición. Lima: Gaceta Jurídica.

LEDESMA NARVÁEZ, Marianella (2008). “Las incongruencias del pleno casatorio civil". Diálogo con la Jurisprudencia. Año 13, núm. 116. Lima.

MOISÁ, Benjamín (2008). “Los llamados 'daños punitivos' en la reforma a la Ley de Defensa del Consumidor de Argentina". Revista Jurídica del Perú 93.

MORALES HERVIAS, Rómulo (2008). “Transacción inválida e inutilidad de la doctrina de los actos propios. A propósito del primer pleno casatorio a favor del abuso de la libertad de estipulación". Diálogo con la Jurisprudencia. Año 13, núm. 116. Lima.

OBANDOBLANCO, Víctor(2007).“Políticajurisdiccional, predictibilidad y doctrina del precedente judicial. Primer Pleno Casatorio 2007". Jus Jurisprudencia 4.

SALVI, Cesare (1998). La responsabilitá civile. Milán: Giuffré.

SOMMA, Alessandro (1998). "Causalitá e danno ambientale". I fatti illeciti, III. Causalitá e danno. Padua: Cedam.

TRIMARCHI, Pietro (1967). Causalitá e danno. Milán: Giuffré.

TUCCI, Giuseppe (2006). Tutela dell'ambiente e diritto alla salute nella prospectiva del Diritto Uniforme Europeo.Studi in onore di Cesare Massimo Bianca. Tomo IV. Milán: Universitá di Catania/ Giuffré Editore.

ZELA VILLEGAS, Aldo (2008). “Una oportunidad perdida: breves apuntes sobre el pleno casatorio". Diálogo con la Jurisprudencia. Año 13, núm. 116. Lima. 